\title{
Long-Term Outcome of Pars Plana Vitrectomy for Retained Posterior Segment Intraocular Foreign Body Secondary to Gunshot Injury
}

\author{
Hammouda Hamdy Ghoraba ${ }^{1,2}$ \\ Mahmoud Leila ${ }^{3}{ }^{3}$ \\ Adel Galal Zaky ${ }^{4}$ \\ Sameh Mohamed Elgouhary ${ }^{4}$ \\ Amin Faisal Ellakwa (iD ${ }^{4}$ \\ Hosam Othman Mansour 5 \\ Mohamed Amin Heikal (iD) 2,6,7 \\ 'Faculty of Medicine, Tanta University, \\ Tanta, Egypt; ${ }^{2}$ Magrabi Eye Hospital, Tanta, \\ Egypt; ${ }^{3}$ Retina Department, Research \\ Institute of Ophthalmology, Giza, Egypt; \\ ${ }^{4}$ Ophthalmology Department, Faculty of \\ Medicine, Menoufia University, Shebin \\ ElKom, Menoufia, Egypt; ${ }^{5}$ Ophthalmology \\ Department, Faculty of Medicine, Al Azhar \\ University - Damietta Branch, New \\ Damietta, Egypt; ${ }^{6}$ Ophthalmology \\ Department, Faculty of Medicine, Benha \\ University, Benha, Egypt; ${ }^{7}$ Vitreoretinal \\ Department, Magrabi Eye Hospital, Eastern \\ province, Khober, KSA
}

Correspondence: Mahmoud Leila I 46 Street 3, 2nd Floor, Flat\#8, Hadabet Al-Ahram, Giza, 12572, Egypt Tel +201286644025

Email mahmoudleila@yahoo.com
Purpose: To report the long-term outcome of pars plana vitrectomy (PPV) for management of retained posterior segment intraocular foreign body (IOFB) secondary to gunshot injury. Methods: This is a retrospective interventional case series including consecutive patients who had PPV for retained posterior segment IOFB secondary to gunshot injury. Main outcome measures were final best-corrected visual acuity (BCVA), long-term globe survival and detection of complications. Spearman correlation analyzed relationships between numerical data. Kruskal-Wallis test compared differences in initial BCVA and final BCVA across variables. Categorical variables were tested using Chi square or Fisher's exact test. P value is significant at 0.05 .

Results: The study included 103 eyes of 103 patients. Mean baseline BCVA was 0.01 decimal unit (2 logMAR). Mean duration from primary repair to PPV was 3 weeks. Mean duration of post-operative follow-up was 60 months. Mean final BCVA was 0.04 decimal unit (1.3 logMAR), p 0.001. Post-operatively, BCVA improved in 58.2\% of patients. Nineteen patients $(18 \%)$ gained $\geq 2$ lines of vision, and 15 patients $(14.5 \%)$ achieved final BCVA of 0.4 decimal unit (logMAR 0.4). All complications were related to the original injury. These included macular scar (19\%), macular pucker $(6 \%)$, recurrent retinal detachment (4\%), subretinal fibrosis (3\%), consecutive optic atrophy (3\%), and PVR (3\%). Phthisis bulbi or sympathetic ophthalmia did not develop in any case.

Conclusion: PPV for removal of IOFB caused by gunshot injury yielded long-term favorable functional outcome with excellent globe survival. Poor initial BCVA, location of IOFB in the posterior pole, associated lens injury and retinal detachment are significant adverse prognostic factors for final BCVA but not for globe survival.

Keywords: Intraocular foreign body; IOFB, ocular gunshot injury, penetrating ocular trauma, IOFB-associated endophthalmitis, pars plana vitrectomy for intraocular foreign body, PPV for IOFB

\section{Introduction}

Ocular injuries by ammunition from firearms entail significant morbidity that frequently leads to poor final visual outcome and globe survival rates. The damage inflicted on intraocular tissues by ballistic projectiles is a consequence of a tandem operation of several mechanisms initiated upon impact with the eye. The combination of high-velocity of the projectile, large amount of kinetic energy and blunt configuration produces severe laceration of the ocular tissues and allows it to penetrate into the posterior segment, where it causes direct injury along its 
trajectory or by ricocheting-off ocular structures. ${ }^{1-6}$ A number of factors determine the anatomic and functional status of the globe after sustaining a gunshot injury. These include, the size of the projectile, the site of entry, extent of damage of intraocular structures, prolapse of uveal tissue, and ensuing complications including inflammatory or chemical reactions produced by retained projectile, proliferative vitreoretinopathy (PVR) along the projectile intraocular track, retinal detachment or endophthalmitis. $^{1,7-13}$ The goals of management are removal of retained intraocular foreign body (IOFB), restoration of the structure of the globe and prevent phthisis bulbi, and management of complications to achieve favorable final visual acuity. The technique of pars plana vitrectomy (PPV) evolved rapidly in the past decades to become the benchmark surgical approach for retained posterior segment IOFB and management of associated complications. PPV allows removal of media opacities as vitreous hemorrhage, elimination of the scaffold for PVR, direct visualization of the IOFB and elimination of its fibrin capsule, and thorough inspection of the retina to detect associated retinal lesions. In addition, PPV helps minimizing the bulk of inflammatory mediators that were released in response to injury through continuous irrigation during surgery. ${ }^{1,6,9,14-17}$ Nevertheless, considerable controversy exists regarding the optimum timing of PPV. Some authors advocate early PPV for retained IOFB to reduce the risk of endophthalmitis and PVR. Other authors advocate delayed PPV to allow for posterior vitreous detachment (PVD) to develop, subsidence of inflammation to reduce the risk of intraoperative hemorrhage, and to allow more complete healing of corneal and/or scleral wounds to allow for a closed system platform and prevent intraoperative hypotony. ${ }^{1,6,9,18-20}$ The aim of the present study is to report the long-term outcome of PPV for management of retained posterior segment IOFB secondary to gunshot injury.

\section{Patients and Methods}

This is a retrospective interventional case series conducted in a retina tertiary center, Magrabi Eye hospital, Tanta, Egypt. All surgical procedures described herein were performed by a single surgeon ( $\mathrm{HG})$. We retrieved the medical records for all consecutive patients who underwent PPV for retained posterior segment IOFB secondary to gunshot injury between February 2011 and January 2014. Data collected included age, gender, entry site of the IOFB, time of initial injury, data of primary repair, duration between primary repair and first presentation at our center, anterior segment complications, retinal impact site, posterior segment complications and associated endophthalmitis. Inclusion criteria were minimum visual acuity of perception of light (PL), and minimum follow-up duration of 2 years after PPV. The study excluded any patient presenting with no PL vision, concomitant anterior segment IOFB, perforating ocular injury, patients who did not complete the minimum required follow-up period and patients with history of previous ocular trauma or low vision from previous ocular disease. Main outcome measures were final best-corrected visual acuity (BCVA), long-term globe survival, and detection of complications. Terminology and classification of ocular trauma followed the Birmingham Eye Trauma Terminology (BETT) and the Ocular trauma Classification Group. Severity of ocular damage was assessed using the Ocular Trauma Score (OTS). ${ }^{21-24}$ All patients received full ophthalmological examination that included anterior segment slitlamp examination, applanation tonometry, posterior segment examination whenever applicable using slit-lamp biomicroscopy and indirect ophthalmoscopy. Ancillary tests were performed for exact localization of the IOFB and for documentation and medicolegal purposes. These included ocular ultrasonography, plain X-ray in sagittal and coronal planes, and thin-slice helical computed tomography scan (CT-scan). BCVA was assessed using decimal notation and later converted to the logarithm of the minimum angle of resolution (logMAR) equivalent for statistical analysis. Visual acuity of counting fingers (CF) was expressed as 0.01 decimal unit; whereas visual acuity of hand movement (HM) or PL was expressed as 0.001 decimal unit.

\section{Surgical Technique}

Primary repair was done for all cases elsewhere. We scheduled PPV at 2 weeks from the date of primary repair to allow for PVD to develop, healing of the entry wound and/or subsidence of suprachoroidal hemorrhage if present. Patients presenting with central corneal entry were operated 4 weeks after the primary repair to allow proper corneal wound healing. Immediate intervention was done in any case if endophthalmitis was present. Surgery consisted of 3-port PPV using either conventional 20-gauge or cannulated 20 - or 23-gauge trocar system. The surgeon performed additional pars plana lensectomy only if the lens was cataractous or if lens touch occurred during surgery. Core vitrectomy and induction of PVD was done if it was not already present. PPV was continued anteriorly as safe as possible. In case intraoperative hemorrhage developed, the surgeon performed 
multiple air-fluid exchange. In cases associated with endophthalmitis; undiluted vitreous sample was obtained by manual aspiration through a syringe fit to the vitrectomy cutter before opening the infusion. The sample was sent for culture and sensitivity. After localizing the IOFB, the surgeon proceeded to clearing vitreous and fibrinous bands around the IOFB. Perfluorocarbon liquid (PFCL) was injected in presence of concomitant retinal detachment to flatten the retina. In addition, PFCL was used to elevate the residual vitreous, to displace subretinal hemorrhage anteriorly, to stabilize the globe during extraction of the IOFB, and to decrease the IOFB impact onto the retina should it fell off the forceps during extraction. Different designs of foreign body forceps were used for holding and removal of the IOFB. Factorymade gunshots in the form of large ball $4.5-5 \mathrm{~mm}$ in size with faceted surfaces were best removed with diamonddusted IOFB forceps due to its good gripping property. Handmade gunshots with flat and sharp edges were removed using 20-gauge serrated vitreoretinal forceps (Figure 1 and Figure 2). In patients with clear crystalline lens, the surgeon resorted to enlargement of the sclerotomy size to extract the IOFB. In aphakic patients the IOFB was removed through a limbal wound. After closure of the enlarged sclerotomy or the limbal wound, $360^{\circ}$ indentation of the retinal periphery was performed to detect any retinal tear. Endolaser photocoagulation was applied around the breaks and $360^{\circ}$ around the periphery of the retina. Air - PFC exchange was performed followed by silicone oil tamponade 5000 centistoke (cSt) in all cases. The post-operative follow-up schedule consisted of out-patient visits at 1 day, 1 week, 1 month, and 3-monthly thereafter. Follow-up examination consisted of assessment of BCVA, IOP, retinal reattachment, and postoperative complications. Fundus examination and color fundus photography were done if possible. Patients who developed recurrent retinal detachment or relentlessly progressive

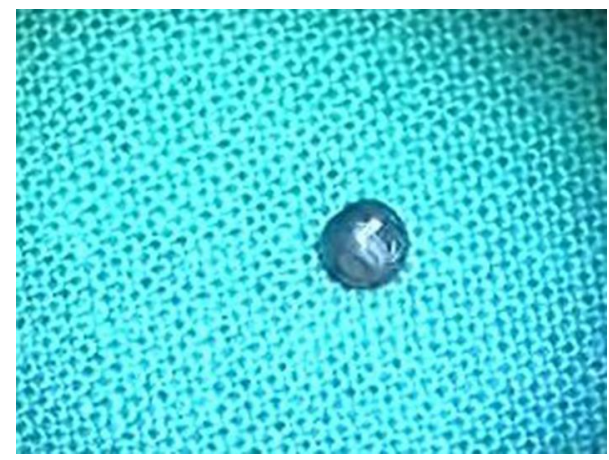

Figure I Factory-made gunshot (rounded ball $4.5-5 \mathrm{~mm}$ with faceted edges).

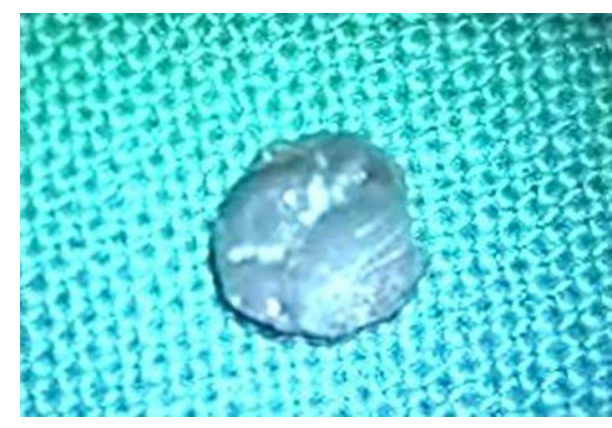

Figure 2 Handmade gunshot with flat and sharp edges.

PVR underwent fluid-air exchange and aspiration of the subretinal fluid through the break. Any residual epiretinal or subretinal membranes were removed followed by injection of $5000 \mathrm{cSt}$ silicone oil. Silicone oil was removed from all cases after minimum period of 6 months.

\section{Statistical Analysis}

Categorical variables were described using counts and percentages. Numerical variables were described using mean and standard deviations or median, minimum and maximum for non-normal distributions (initial visual acuity, final visual acuity). Relationships between numerical data were analyzed by Spearman correlation. Differences in initial visual acuity and final visual acuity across variables were compared using Kruskal-Wallis test with pairwise comparisons to detect the significant pairs. Categorical variables were tested using Chi square or Fisher's exact test. The analysis was done at significance level of 0.05 . Significant values were adjusted by Bonferroni correction for multiple tests in the pairwise comparisons.

\section{Results}

We reviewed the medical records of 130 patients. We excluded 27 patients. Eleven patients presented with no PL vision, and another 16 patients did not complete the required follow-up period. Statistical analysis was done for 103 eyes of 103 patients.

\section{Baseline Characteristics of Study Participants}

Male gender constituted 95\% (98 patients) of the study sample. Mean age was 26 years (range $12-45$ years; SD 8.3). Zone I injury (isolated corneal wound) was encountered in 59 patients $(57 \%$ ), zone II injury (wound 
involving the sclera within $5 \mathrm{~mm}$ from the corneoscleral limbus) was encountered in 20 patients (19\%), and zone III injury (wound is located posterior to zone II) was encountered in 24 patients $(23 \%)$. Mean duration from primary repair to PPV was 3 weeks (range 1-6 weeks; SD 0.9). The main associated anterior segment pathology was cataract (48\%), followed by lens subluxation $(21 \%)$, aphakia (19\%), and hyphema (12\%). The main associated posterior segment pathology encountered was retinal detachment (22\%), followed by vitreous hemorrhage $(20 \%)$, suprachoroidal hemorrhage $(13 \%)$, endophthalmitis (9\%), macular hole (6\%), and combined retinal detachment and suprachoroidal hemorrhage (5\%). Twenty-six patients $(25 \%)$ did not present with additional posterior segment pathology other than the IOFB impact. The most common impact site in the retina was located nasally (46\%), followed by the macular area (31\%), and temporally (23\%). Mean OTS was 44 (range 26-67; SD 13.3). Mean baseline BCVA was 0.01 decimal unit (2 logMAR), range 0.001-0.4 decimal units; SD 0.07. Mean duration of post-operative follow-up was 60 months (range 30-84; SD 15.2). Post-operatively, 60 patients $(58.2 \%)$ experienced improvement in BCVA, 38 patients (37\%) had stable BCVA, and 5 patient (5\%) had deteriorated BCVA. Mean final BCVA was 0.04 decimal unit (1.3 logMAR), range 0.001-0.25 decimal units; SD 0.07; p 0.001. Postoperatively, we did not have complications related to surgery. All complications were related to the original injury. These included macular scar (19\%), macular pucker $(6 \%)$, recurrent retinal detachment (4\%), subretinal fibrosis $(3 \%)$, consecutive optic atrophy (3\%), and PVR (3\%). Phthisis bulbi or sympathetic ophthalmia did not develop in any case (Table 1 and Table 2).

\section{Statistical Correlation of Studied Variables}

\section{Correlation Between Initial BCVA and Final BCVA}

Statistical analysis revealed a positive correlation between initial BCVA and final BCVA, p 0.001. Better initial BCVA was associated with better final BCVA (Figure 3).

\section{Correlation Between Time Lapse Between Primary Repair and PPV and Final BCVA}

Statistical analysis revealed a negative correlation between longer duration and final BCVA, p 0.001. The more the
Table I Baseline Characteristics of Study Participants

\begin{tabular}{|c|c|}
\hline Baseline Characteristics & $\mathbf{N}(\%)$ \\
\hline \multicolumn{2}{|l|}{ Age, years } \\
\hline$<20$ & $20(19)$ \\
\hline $20-40$ & $79(77)$ \\
\hline$>40$ & $4(4)$ \\
\hline \multicolumn{2}{|l|}{ Gender } \\
\hline Male & $98(95)$ \\
\hline Female & $5(5)$ \\
\hline \multicolumn{2}{|l|}{ Entry wound } \\
\hline Zone I & $59(57)$ \\
\hline Zone II & $20(19)$ \\
\hline Zone III & $24(23)$ \\
\hline \multicolumn{2}{|l|}{ Duration from primary repair to PPV (weeks) } \\
\hline$<3$ & $13(13)$ \\
\hline $3-4$ & $76(74)$ \\
\hline$>4$ & $14(14)$ \\
\hline \multicolumn{2}{|l|}{ Retinal impact site } \\
\hline Nasal & $47(46)$ \\
\hline Temporal & $24(23)$ \\
\hline Macular & $32(3 I)$ \\
\hline \multicolumn{2}{|l|}{ Anterior segment pathology } \\
\hline Cataract & $49(48)$ \\
\hline Lens subluxation & $22(21)$ \\
\hline Aphakia & $20(19)$ \\
\hline Hyphema & $12(12)$ \\
\hline \multicolumn{2}{|l|}{ Posterior segment pathology } \\
\hline Retinal detachment & $23(22)$ \\
\hline Vitreous hemorrhage & $21(20)$ \\
\hline $\mathrm{SCH}$ & $13(13)$ \\
\hline Endophthalmitis & $9(9)$ \\
\hline Macular hole & $6(6)$ \\
\hline Combined retinal detachment and $\mathrm{SCH}$ & $5(5)$ \\
\hline None & $26(25)$ \\
\hline \multicolumn{2}{|l|}{ BCVA (decimal) } \\
\hline 0.001 & $98(95)$ \\
\hline 0.1 & $\mathrm{I}(\mathrm{I})$ \\
\hline 0.4 & $4(4)$ \\
\hline \multicolumn{2}{|l|}{ Follow-up duration (months) } \\
\hline $30-50$ & $35(34)$ \\
\hline$>50-70$ & $35(34)$ \\
\hline$>70$ & $33(32)$ \\
\hline
\end{tabular}

Abbreviations: BCVA, best-corrected visual acuity; PPV, pars plana vitrectomy; $\mathrm{SCH}$, suprachoroidal hemorrhage.

time lapse between primary repair and PPV the worse the final BCVA achieved (Figure 4). 
Table 2 Post-Operative Anatomical and Functional Outcomes

\begin{tabular}{|l|r|}
\hline Outcome & N (\%) \\
\hline BCVA (decimal) & \\
$<0.05$ & $76(74)$ \\
$0.05-0.1$ & $12(12)$ \\
0.4 & $15(14.5)$ \\
\hline Complications & \\
Macular scar & $20(19)$ \\
Macular pucker & $6(6)$ \\
Recurrent retinal detachment & $4(4)$ \\
Sub-retinal fibrosis & $3(3)$ \\
Consecutive optic atrophy & $3(3)$ \\
PVR & $3(3)$ \\
None & $64(62)$ \\
\hline
\end{tabular}

Abbreviations: BCVA, best-corrected visual acuity; PVR, proliferative vitreoretinopathy.

\section{Correlation Between Entry Zone and Retinal Impact Site of the IOFB}

Entry zone of the IOFB correlated significantly with retinal impact site whenever the location was in the nasal or temporal retina but did not correlate with IOFB impact in the macular area, p 0.003, 0.006 and 0.15 , respectively.

\section{Correlation Between Entry Zone of the IOFB and BCVA}

Entry zone of the IOFB correlated significantly with initial and final BCVA, p 0.04 and $\leq 0.001$, respectively. However, posthoc analysis revealed that only Zone Ientry versus Zone II entry and Zone II entry versus Zone III entry correlated significantly with final BCVA, $\mathrm{p} \leq 0.001$ and 0.001 , respectively (Table 3).

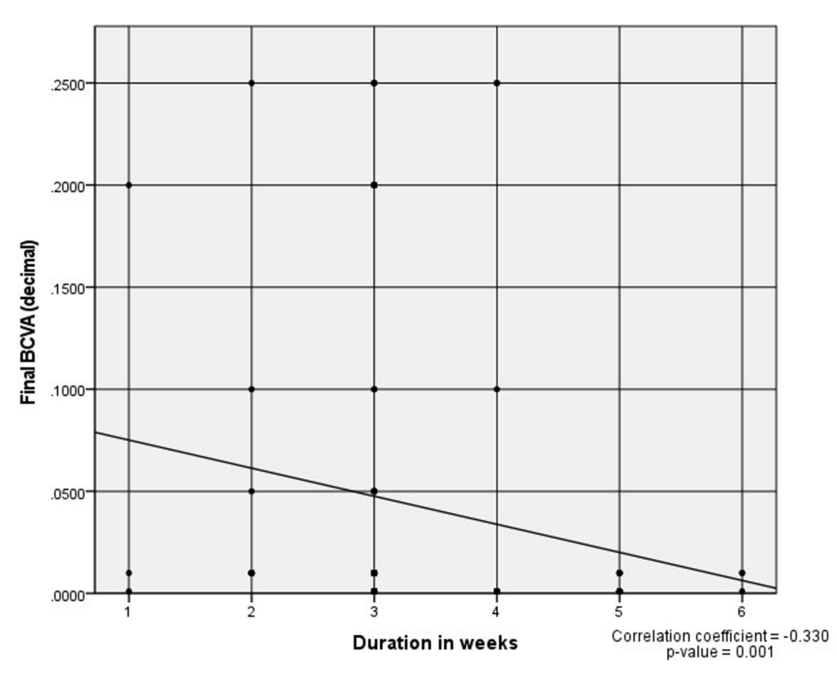

Figure 3 Spearman correlation between duration in weeks and final BCVA.

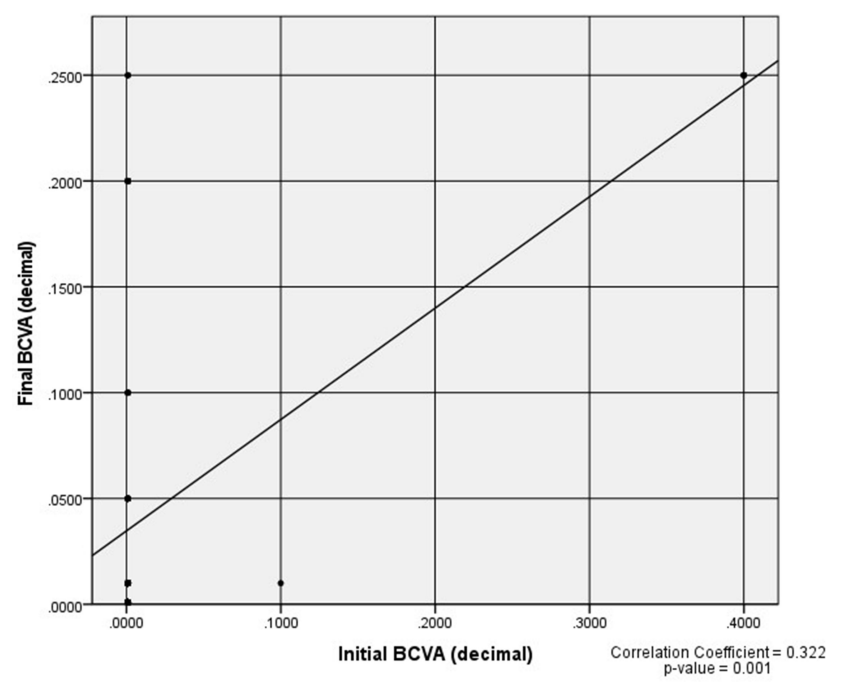

Figure 4 Spearman correlation between initial BCVA and final BCVA.

Correlation Between Retinal Impact Site of the IOFB and Final BCVA and Incidence of Complications

IOFB located in the macula was associated with the worst final BCVA compared to IOFB located in the temporal or nasal retina, $p<0.001$. IOFB located in the macula was associated with the highest incidence of complications, whereas IOFB located in the nasal retina was associated with the least incidence of complications, $\mathrm{p}<0.001$.

\section{Correlation Between Associated Anterior Segment} and Posterior Segment Pathology and Final BCVA

Lens subluxation and retinal detachment were associated with the worst final BCVA, p 0.001; whereas hyphema and vitreous hemorrhage were associated was the best final BCVA, p 0.001 (Table 4 and Table 5).

\section{Discussion}

In the present study, PPV and IOFB removal yielded favorable visual outcome. At the final follow-up examination the mean final BCVA improved significantly compared to baseline BCVA, with $58.2 \%$ of patients experiencing improvement in BCVA. Nineteen patients (18\%) gained $\geq 2$ lines of vision and 15 patients (14.5\%) achieved final BCVA of 0.4 decimal unit (logMAR 0.4). In terms of globe survival, none of the patients included in the present study developed phthisis bulbi or sympathetic ophthalmia. All complications detected were attributed to the IOFB. Prognostic factors that were significant predictors of worst visual outcome included poor initial BCVA (p 0.001), long duration between primary repair and PPV (p 0.001), impact of IOFB in the macular area $(\mathrm{p}<0.001)$, 
Table 3 Correlation Between Entry Zone of IOFB, Impact Site of IOFB, Initial BCVA and Final BCVA

\begin{tabular}{|c|c|c|c|c|c|}
\hline & & Zone I & Zone II & Zone III & \multirow[t]{2}{*}{ P-value } \\
\hline & & No. $=59$ & No. $=20$ & No. $=24$ & \\
\hline \multirow[t]{3}{*}{ Impact site } & Nasal & $22(37 \%)$ & $16(80 \%)$ & $9(37.5 \%)$ & 0.003 \\
\hline & Temporal & $20(34 \%)$ & $0(0 \%)$ & $4(17 \%)$ & 0.006 \\
\hline & Macular & 17 (29\%) & $4(20 \%)$ & II (46\%) & 0.15 \\
\hline \multirow[t]{2}{*}{ Initial BCVA } & Mean \pm SD & $0.009 \pm 0.05$ & $0.06 \pm 0.1$ & $0.001 \pm 0.000$ & \multirow[t]{2}{*}{0.04} \\
\hline & Range & $0.00 \mathrm{I}-0.4$ & $0.001-0.4$ & $0.001-0.001$ & \\
\hline \multirow[t]{4}{*}{ Final BCVA } & Mean \pm SD & $0.025 \pm 0.05$ & $0.1 \pm 0.1$ & $0.03 \pm 0.06$ & \multirow[t]{2}{*}{$\leq 0.001$} \\
\hline & Range & $0.00 \mathrm{I}-0.25$ & $0.00 \mathrm{I}-0.25$ & $0.00 \mathrm{I}-0.2$ & \\
\hline & \multicolumn{5}{|c|}{ Post-Hoc analysis by Mann-Whitney test } \\
\hline & $\mathrm{PI}$ & & P2 & \multicolumn{2}{|c|}{ P3 } \\
\hline Initial BCVA & 0.06 & & 0.4 & \multicolumn{2}{|c|}{0.05} \\
\hline Final BCVA & $\leq 0.001$ & & 0.85 & \multicolumn{2}{|c|}{0.001} \\
\hline
\end{tabular}

Notes: PI, Zone I entry versus Zone II entry; P2, Zone I entry versus Zone III entry; P3, Zone II entry versus Zone III entry.

Abbreviations: BCVA, best-corrected visual acuity; SD, standard deviation.

associated subluxation of the crystalline lens $(p<0.001)$, and retinal detachment ( $\mathrm{p}$ 0.001). Our visual results are better than Colyer et al, ${ }^{1}$ Zhang et al, ${ }^{3}$ Benson and Machemer, ${ }^{7}$ and Falavarjani et al ${ }^{15}$ who reported improvement in final visual acuity in $53.4 \%, 54.33 \%, 32 \%$, and $44.6 \%$, respectively. Our visual results are comparable to Bai et $\mathrm{al}^{4}$ and less than those reported by Justin et al, ${ }^{12}$ and Ghoraba et $\mathrm{al}^{14}$ who reported final visual acuity of $58.3 \%$, $64.9 \%$, and $69.23 \%$, respectively. It is noteworthy that $95 \%$ of our patients presented with visual acuity of $\mathrm{HM}$ or $\mathrm{CF}$, which was the reason approximately $85 \%$ of our patients scored final BCVA of $\leq 0.1$ decimal unit $(1.0$ $\log$ MAR). Our findings are congruous with Colyer et al, ${ }^{1}$ Bai et $a{ }^{4}{ }^{4}$ Agrawal et al, ${ }^{13}$ and Jonas et $\mathrm{al}^{18}$ who found that initial visual acuity is a significant prognostic factor

Table 4 Correlation Between Anterior Segment Pathology and Final BCVA

\begin{tabular}{|l|c|c|c|c|}
\hline \multirow{2}{*}{$\begin{array}{l}\text { Anterior } \\
\text { Segment }\end{array}$} & \multicolumn{3}{|c|}{ Final BCVA (Decimal) } & \multirow{2}{*}{ p-value } \\
\cline { 2 - 4 } & Median & Minimum & Maximum & \\
\hline Lens subluxation & 0.00 & 0.00 & 0.01 & $<0.001$ \\
Hyphema & 0.05 & 0.05 & 0.25 & \\
Aphakia & 0.01 & 0.00 & 0.10 & \\
Cataract & 0.01 & 0.00 & 0.25 & \\
\hline
\end{tabular}

Abbreviation: BCVA, best-corrected visual acuity. for final visual acuity. In contrast, Nicoară et $\mathrm{al}^{16}$ did not detect significant correlation between initial and final visual acuity. In the present study, long duration before PPV was a significant adverse prognostic factor for final BCVA. In fact, the duration between primary repair and PPV was $\geq 3$ weeks in $87 \%$ of our patients, and $\geq 4$ weeks in $26.2 \%$. Nevertheless, our protocol for management of IOFB entailed waiting for at least 2 weeks before performing PPV to allow maximum resolution of tissue inflammation and edema, and to allow time for spontaneous PVD induction. We advocate this approach in all cases of IOFB except cases presenting with associated endophthalmitis, to allow more controlled surgery and to minimize intraoperative complications as hemorrhage and retinal tears. An important consideration in interpreting the significance of time duration in relation to final visual outcome reported in our results is the mode of calculating the duration particularly that all patients included in the present study had their primary repair surgery performed elsewhere. The retrospective design of the study dictated acquisition of information on the time duration factor based on history provided by the patients or their parents regarding the date of primary repair or the time they waited between initial injury and primary repair. This meant that the duration reported herein might be in fact longer. Despite the long duration reported in the present study, we detected 
Table 5 Correlation Between Posterior Segment Pathology and Final BCVA

\begin{tabular}{|l|c|c|c|c|}
\hline \multirow{2}{*}{$\begin{array}{l}\text { Posterior Segment } \\
\text { Pathology }\end{array}$} & \multicolumn{3}{|c|}{ Final BCVA (Decimal) } & \multirow{2}{*}{ p-value } \\
\cline { 2 - 4 } & Median & Minimum & Maximum & \\
\hline Retinal detachment & 0.00 & 0.00 & 0.01 & \multirow{2}{*}{0.001} \\
Vitreous hemorrhage & 0.05 & 0.00 & 0.20 & \\
SCH & 0.01 & 0.00 & 0.01 & \\
Endophthalmitis & 0.01 & 0.00 & 0.01 & \\
Macular hole & 0.01 & 0.01 & 0.05 & \\
Combined retinal & 0.01 & 0.00 & 0.01 & \\
detachment and SCH & & & & \\
None & 0.01 & 0.00 & 0.25 & \\
\hline
\end{tabular}

Abbreviations: BCVA, best-corrected visual acuity; $\mathrm{SCH}$, suprachoroidal hemorrhage.

endophthalmitis in 9 patients (9\%) at presentation. This rate is significantly less than the rates reported by Zhang et $a{ }^{3}{ }^{3}$ FRIENDS group ${ }^{10}$ and Nicoară et al, ${ }^{16}$ who had endophthalmitis rates of $16.76 \%, 53 \%$, and $28.57 \%$, respectively. In accordance with our finding, Colyer et $\mathrm{al}^{1}$ did not detect any case of endophthalmitis in their study. In fact, the authors recommended that prompt primary repair, systemic antibiotics and delayed removal of IOFB might be necessary to allow for more controlled surgery compared to earlier intervention. Contrary to this approach, Chaudhry et $\mathrm{al}^{9}$ mentioned that delay in IOFB removal more than 2 days increased the risk of endophthalmitis. The authors reported endophthalmitis rate $7.5 \%$. Jonas et $\mathrm{al}^{18}$ found that removal of IOFB within 24 hours significantly decreased the risk of endophthalmitis. The authors reported endophthalmitis rate of $5.4 \%$. In the present study delayed removal of IOFB yielded endophthalmitis rates that were comparable to Chaudhry et $\mathrm{al}^{9}$ and Jonas et al. ${ }^{18}$ Moreover, the nature of IOFB in all patients in the present study was ballistic projectile, which has a high core temperature that renders it relatively sterile. ${ }^{1}$ Interestingly, in our study we retrieved eye lashes from the vitreous cavity in all patients with endophthalmitis. We purport that the cause of endophthalmitis was actually various particulate matter that were carried from outside the eye to the vitreous cavity by the projectile upon penetration. In our study, lens injury was a significant adverse prognostic factor for final visual acuity. This finding is in accordance with Agrawal et al. ${ }^{13}$ However, Bai et $\mathrm{al}^{4}{ }^{4}$ and Falavarjani et $\mathrm{al}^{15}$ found no significant association between lens injury and final visual acuity. Macular IOFB impact and retinal detachment were other significant prognostic factors for poor final visual acuity in the present study. Similar findings were reported by Zhang et al, ${ }^{3}$ Bai et al, ${ }^{4}$ Nicoară et al, ${ }^{16}$ and Jonas et al. ${ }^{18}$ The follow-up duration of the present study is one of the longest reported in literature, which adds to the strength of our results. Nevertheless, the study had important limitations. These included its retrospective design and the fact that all patients were referred to our center after having the primary repair performed elsewhere. This dictated considerable inaccuracies in retrieving important data regarding initial visual acuity, OTS calculation, antibiotic regimen received, different therapeutic approaches and variable surgical skills of their primary surgeons. These data variation might have introduced important bias during statistical analysis and determination of different prognostic factors and their relative correlations.

\section{Conclusion}

PPV for removal of IOFB caused by gunshot injury yielded long-term favorable functional outcome with excellent globe survival. In absence of endophthalmitis, delayed secondary intervention for IOFB removal allows more controlled surgery, promotes better surgical outcome, and does not impose additional risks. Poor initial BCVA, location of IOFB in the posterior pole, associated lens injury and retinal detachment are significant adverse prognostic factors for final BCVA but not for globe survival.

\section{Institution}

The study was conducted in a retina tertiary care center (Magrabi Eye Hospital), Tanta, Egypt.

\section{Data Sharing Statement}

The data collected from history taking and clinical examination of patients recruited in the current study are confidential. Access to these data is restricted by Magrabi Eye Hospital in accordance with patients' data protection policy. Data are available for researchers who meet the criteria for access to confidential data through contacting the medical director Professor Hammouda Ghoraba hghoraba@email.com.

\section{Statement of Ethics}

The study was approved by the institution review board of Magrabi Eye Hospital, Tanta, Egypt.

The study adhered strictly to the tenets of the Declaration of Helsinki of 1975 and the revision of 2013.

The study required that all participants received a thorough explanation of the surgical maneuvers entailed, possible outcome, and expected complications and signed 
an informed consent prior to enrollment either in person or via the legal custodian.

\section{Disclosure}

The authors report no conflicts of interest in this work.

\section{References}

1. Colyer MH, Weber ED, Weichel ED, et al. Delayed intraocular foreign body removal without endophthalmitis during operations Iraqi freedom and enduring freedom. Ophthalmology. 2007;114:1439-1447. doi:10.1016/j.ophtha.2006.10.052

2. Ehlers JP, Kunimoto DY, Ittoop S, Maguire JI, Ho AC, Regillo CD. Metallic intraocular foreign bodies: characteristics, interventions, and prognostic factors for visual outcome and globe survival. Am J Ophthalmol. 2008;146:427-433. doi:10.1016/j.ajo.2008.05.021

3. Zhang Y, Zhang M, Jiang C, Qiu HY. Intraocular foreign bodies in China: clinical characteristics, prognostic factors, and visual outcomes in 1421 eyes. Am $J$ Ophthalmol. 2011;152:66-73. doi:10.1016/j.ajo.2011.01.014

4. Bai HQ, Yao L, Meng XX, Wang YX, Wang DB. Visual outcome following intraocular foreign bodies: a retrospective review of 5-year clinical experience. Eur J Ophthalmol. 2011;21:98-103. doi:10.5301/ EJO.2010.2210

5. Khoueir Z, Cherfan G, Assi A. Vitreoretinal surgery for shotgun eye injuries: outcomes and complications. Eye. 2015;29:881-887. doi:10.1038/eye.2015.46

6. Loporchio D, Mukkamala L, Gorukanti K, Zarbin M, Langer P, Bhagat N. Intraocular foreign bodies: a review. Surv Ophthalmol. 2016;61:582-596. doi:10.1016/j.survophthal.2016.03.005

7. Benson WE, Machemer R. Severe perforating injuries treated with pars plana vitrectomy. Am J Ophthalmol. 1976;81:728-732. doi:10.1016/0002-9394(76)90354-8

8. Knox FA, Best RM, Kinsella F, et al. Management of endophthalmitis with retained intraocular foreign body. Eye. 2004;18:179-182. doi:10.1038/sj.eye. 6700567

9. Chaudhry IA, Shamsi FA, Al-Harthi E, Al-Theeb A, Elzaridi E, Riley FC. Incidence and visual outcome of endophthalmitis associated with intraocular foreign bodies. Graef Arch Clin Exp Ophthalmol. 2008;246:181-186. doi:10.1007/s00417-007-0586-5

10. Cornut P-L, Youssef EB, Bron A; The French Institutional Endophthalmitis Study (FRIENDS) group. A multicenter prospective study of post-traumatic endophthalmitis. Acta Ophthalmol. 2013;91:475-482. doi:10.1111/j.1755-3768.2011.02349.x

11. Guevara -villarreal DA, Rodríguez-Valdés PJ. Posterior segment intraocular foreign body: extraction surgical techniques, timing, and indications for vitrectomy. $J$ Ophthalmol. 2016;2016:1-5. doi:10.1155/2016/2034509
12. Justin GA, Baker KM, Brooks DI, Ryan DS, Weichel ED, Colyer MH. Intraocular foreign body trauma in operation Iraqi freedom and operation enduring freedom 2001-2011. Ophthalmology. 2018;125:1675-1682. doi:10.1016/j.ophtha.2018.06.006

13. Agrawal R, Wei HS, Teoh S. Prognostic factors for open globe injuries and correlation of ocular trauma score at a tertiary referral eye care centre in Singapore. Indian J Ophthalmol. 2013;61:502-506. doi:10.4103/0301-4738.119436

14. Ghoraba HH, Ellakwa AF, Ghali AA, Abdel Fattah HM. Long-term results of $360 \mathrm{~A}^{\circ}$ scleral buckling and vitrectomy with silicone oil tamponade for management of gunshot-perforating ocular injury. Eye. 2012;26:1318-1323. doi:10.1038/eye.2012.150

15. Falavarjani KG, Hashemi M, Modarres $M$, et al. Vitrectomy for posterior segment intraocular foreign bodies, visual and anatomical outcomes. Middle East Afr J Ophthalmol. 2013;20:244-247. doi:10.4103/0974-9233.114803

16. Nicoară SD, Irimescu L, Călinici T, Cristian C. Intraocular foreign bodies extracted by pars plana vitrectomy: clinical characteristics, management, outcomes and prognostic factors. BMC Ophthalmol. 2015;15(151):1-8. doi:10.1186/s12886-015-0128-6

17. Ghoraba HH, Mansour HO, Heikal MA, Abdelfattah HM, Elgemai EM. Comparison between pars plana vitrectomy with versus without a $360^{\circ}$ episcleral band in the management of gunshot perforating eye injury. Retina. 2016;36:596-602. doi:10.1097/ IAE. 0000000000000739

18. Jonas JB, Knorr HLJ, Budde WM. Prognostic factors in ocular injuries caused by intraocular or retrobulbar foreign bodies. Ophthalmology. 2000;107:823-828. doi:10.1016/S0161-6420(00) 00079-8

19. Yeh S, Colyer MH, Weichel ED. Current trends in the management of intraocular foreign bodies. Curr Opin Ophthalmol. 2008;19:225-233. doi:10.1097/ICU.0b013e3282fa75f1

20. Kanu LN, Jiang Y, Gonzalez AFV, Mieler WF. Visual and anatomic outcomes in perforating ocular injuries. $J$ Vitreoretin Dis. 2019;3:428-437. doi:10.1177/2474126419865992

21. Kuhn F, Morris R, Witherspoon CD, Heimann K, Jeffers JB, Treister G. A standardized classification of ocular trauma. Ophthalmology. 1996;103:240-243. doi:10.1016/S0161-6420(96) 30710-0

22. Kuhn F, Morris R, Witherspoon CD. Birmingham Eye Trauma Terminology (BETT): terminology and classification of mechanical eye injuries. Ophthalmol Clin North Am. 2002;15:139-143. doi:10.1016/S0896-1549(02)00004-4

23. Kuhn F, Maisiak R, Mann L, Mester V, Morris R, Witherspoon CD. The Ocular Trauma Score (OTS). Ophthalmol Clin North Am. 2002;15:163-165. doi:10.1016/S0896-1549(02)00007-X

24. Pieramici DJ, Sternberg P, Aaberg TM, et al. A system for classifying mechanical injuries of the eye (globe). Am $J$ Ophthalmol. 1997;123:820-831. doi:10.1016/S0002-9394(14)71132-8
Clinical Ophthalmology

\section{Publish your work in this journal}

Clinical Ophthalmology is an international, peer-reviewed journal covering all subspecialties within ophthalmology. Key topics include: Optometry; Visual science; Pharmacology and drug therapy in eye diseases; Basic Sciences; Primary and Secondary eye care; Patient Safety and Quality of Care Improvements. This journal is indexed on PubMed
Central and CAS, and is the official journal of The Society of Clinical Ophthalmology (SCO). The manuscript management system is completely online and includes a very quick and fair peer-review system, which is all easy to use. Visit http://www.dovepress.com/ testimonials.php to read real quotes from published authors.

\section{Dovepress}

